\title{
PROJETO BIÊNIO SIMONIANO EM CARTAZ
}

Lúcia Bergamaschi Costa Weymar, Dra

Centro de Artes - Universidade Federal de Pelotas

luciaweymar@gmail.com

Resumo: Projeto de Cartaz - disciplina por mim ministrada para alunos de primeiro semestre dos Cursos de Design Gráfico e Digital no Centro de Artes da Universidade Federal de Pelotas - propõe uma metodologia de ensino e de projeto cujos processos e resultados têm se mostrado bastante qualificados. As propostas sempre variam em temática, mas sua estrutura é recorrente: após inúmeros encontros teóricos com foco na história do cartaz, os alunos, divididos em duplas, devem projetar dois cartazes independentes, mas em diálogo; no primeiro cartaz é homenageado um designer de perfil moderno e, no segundo, um pós-moderno. $\mathrm{O}$ artigo "Projeto Biênio Simoniano em Cartaz" objetiva apresentar a proposta cuja temática versa sobre os 150 de nascimento e 100 anos de morte do importante escritor gaúcho João Simões Lopes Neto.

Palavras-chave: Cartaz; Designers modernos, Designers pós-modernos, Biênio Simoniano, Design autoral.

\begin{abstract}
Poster Design - discipline for me taught for students of the first semester of Graphic and Digital Design Courses in Center of Arts of Pelotas Federal University - proposes a teaching and project methodology whose proceedings and results have been quite skilled. The proposal always varies in thematics, but its structure is recurrent: after numerous theoretical meetings with focus in the history of the poster, the students, divided into pairs, should design two independent but in dialogue posters; in the first poster a modern profile designer is honored and in the second, a postmodern designer. The article "Biennium Simoniano Project in Poster" aims to submit a proposal whose theme is about the 150 birth and 100 years since the death of the relevant writer from Rio Grande do Sul called João Simões Lopes Neto.
\end{abstract}

Keywords: Poster, Modern designers, Postmodern designers, Biennium Simoniano, Authorship design. 


\section{INTRODUÇÃO}

E mandei fazer um laço, Da casaca do jacaré, P'ralaçar meu boi barroso, No redomão pangaré (João Simões Lopes Neto)

A partir de uma pequena reforma curricular os Cursos de Design Gráfico e Digital do Centro de Artes da Universidade Federal de Pelotas (UFPEL) criaram a disciplina denominada Projeto de Cartaz para alunos de primeiro semestre. Tal medida surgiu face à necessidade de contemplar a importante peça gráfico/digital em disciplina específica uma vez que cartazes eram projetados em instâncias variadas do curso, mas sem foco per se. Desde 2014, como professora responsável, tenho variado suas temáticas, mas a metodologia que venho desenvolvendo se apresenta perene em sua estrutura mais basilar. Tal estrutura refere-se à organização da disciplina do seguinte modo: primeiramente, encontros iniciais com abordagem teórica em teoria e história do cartaz, e, a seguir, divisão da turma em duplas para a proposição dos exercícios práticos. A produção prática é concernente ao projeto de dois cartazes interdependentes, isto é, unidades autônomas, mas em diálogo. No primeiro cartaz a dupla de alunos deve homenagear um designer de estilo, ou viés, moderno e, no segundo, um de estilo pós-moderno (importa deixar claro, de súbito, que entendemos o moderno e o pós-moderno muito mais numa premissa cultural do que cronológica).

Isto posto, temas como Copa do Mundo no Brasil (2014/1), aniversário de quinze anos dos cursos (2014/2), enunciados proferidos por designers famosos (2015/2), comemorações acerca dos 400 anos de morte de William Shakespeare e de Miguel de Cervantes (2016/1 e 2016/2), têm sido escolhidos de acordo com a agenda do semestre. Porém, os resultados de uma proposta em específico entusiasmaram-me sobremaneira - tanto pelos produtos gráficos decorrentes como pela possibilidade de divulgação da literatura e do design gaúchos, a ponto de submetê-los à apreciação do P\&D 2016.

Em 2015 completaram-se 150 anos de nascimento do escritor gaúcho João Simões Lopes Neto e, em 2016, 100 anos da sua morte. Considerado por estudiosos e críticos como o maior autor regionalista do Rio Grande do Sul, Simões Lopes Neto buscou, em sua produção literária - Cancioneiro Guasca (1910), Contos Gauchescos (1912), Lendas do Sul (1913) e Casos de Romualdo (1914) - valorizar a história do gaúcho e suas tradições. Pela importância destas datas, a Secretaria de Estado da Cultura (SEDAC), em parceria com a Prefeitura de Pelotas e com o Instituto Simões Lopes Neto, criou o projeto que deu origem ao decreto intitulado Biênio Comemorativo, a realizar-se em todo território nacional.

A partir dessa temática a disciplina Projeto de Cartaz apresentou à turma de calouros do Curso de Design Gráfico, no primeiro semestre de 2015, a proposta de ensino denominada Projeto Biênio Simoniano.

O objetivo deste artigo é apresentar aos pesquisadores e interessados no ensino do design parte daquela experiência à luz da pesquisa bibliográfica sobre história do design (MEGGS, 1998; JONG, 2010; BARNICOAT, 1999) e da metodologia projetual em cartaz (FRASCARA, 2006; LUPTON; PHILLIPS, 2008). 


\section{PROJETO BIÊNIO SIMONIANO}

Como desenvolver uma metodologia de ensino que introduza alunos recém ingressantes em cursos superiores de design ao universo teórico e de prática projetual de cartazes, contextualizando-os tanto no escopo da disciplina quanto estimulando, neles, a importância de um aprendizado de design atrelado às múltiplas esferas da cultura e da expressão artística e autoral?

O artigo denominado "Projeto Biênio Simoniano em Cartaz", sintonizado à agenda cultural do estado do Rio Grande do Sul, tenta responder a questão na medida em que apresenta uma metodologia que vem sendo desenvolvida em disciplina referente ao tema. Para tal, apresento, a seguir, a descrição de experiência realizada em sala de aula, e suas especificidades.

Em se tratando da estrutura basilar, acima comentada, é preciso deixar claro que ao longo de seis encontros de duas horas/aula semanais o debate teórico da disciplina sempre envolve tópicos relativos a 1) Teoria do cartaz, funções e objetivos; 2) Cartaz no Século $X$, Xilografias, Cartaz Oriental, Renascimento, Litografias, Arts and Crafts, Art Nouveau; 3) Cartaz e Design Russo, Bauhaus, Cubismo; 4) Cartaz da Segunda Guerra, Cartaz Publicitário, Cartaz Psicodélico; 5) Cartaz Polonês, Cartaz Japonês, Cartaz Político, Cartazes portugueses durante a ditadura de Salazar, Cartazes de Maio de 1968 na França e da Ditadura Militar no Brasil e 6) Cartaz Brasileiro.

Outrossim, a análise das imagens contidas em tais tópicos - realizada pelos alunos e pela professora - conta recorrentemente com o aporte teórico de Ambrose (2009) e Lupton e Phillips (2008) e foca nos quatro princípios do design, quais sejam, tipografia, cor, composição e imagem. Tais princípios são aprofundados na tentativa de organizar tais imagens a partir das categorias "cartazes modernos" e "cartazes pósmodernos". Ao compreender a modernidade e a pós-modernidade muito mais a partir de um viés cultural do que cronológico evitamos um discurso esquemático e dual. Porém, as diferentes características entre os dois paradigmas são evidenciadas na medida em que as regras do design moderno são quebradas pela pós-modernidade, ou seja, tipografias, cor, composição e imagem 1) se complexificam, 2) passam a aceitar a pluralidade em detrimento da unidade, 3) surgem elaboradas e ornamentais e não mais simplificadas e puramente funcionais, e, enfim, 4) rompem com sistemas de legibilidade, contraste, organização espacial e se posicionam arbitrárias, independentes e livres dos preceitos modernistas "menos é mais" ou "a forma segue a função" (MEGGS, 1998).

Após perpassar essa primeira instância, dita teórica, a turma de 2015/1 composta por vinte e três alunos ingressantes do Curso de Design Gráfico e dividida em dez duplas e um trio -, passou à prática solicitada.

A metodologia projetual escolhida para nortear a atividade prática da disciplina tem se baseado nas dez etapas projetuais propostas por Frascara (2006). Na primeira etapa, denominada "Encomenda do projeto", o briefing apresentado solicita que, a partir das perguntas "Se eu fosse, por exemplo Moholy-Nagy, como eu projetaria?" e "Se eu fosse, por exemplo Sagmeister, como eu projetaria?", cada dupla deve escolher dois designers de estilos gráficos diferentes (um moderno e outro pós-moderno) e projetar dois cartazes, um para cada (no caso do trio de alunos, três cartazes). Os cartazes têm que dialogar entre si, seja de modo sintático, seja semântico! É um exercício de design autoral que prescinde de clientes e cuja preocupação principal refere-se à própria expressividade dos alunos. 
As etapas seguintes "Coleta de dados" (pesquisa sobre os designers escolhidos), "Segunda definição do problema" (primeira proposta apresentada pelos alunos após a pesquisa na qual já foi realizada análise, interpretação e organização da informação coletada e definidos os objetivos, alcance, contextos, mensagem e formatos), "Especificação do desempenho do design" e "Terceira definição do problema" (segunda proposta apresentada e definidora da estratégia a ser seguida), foram realizadas em apenas um encontro na medida em que as tarefas são sempre, igualmente, realizadas extraclasses.

A seguir, os alunos passaram à etapa prática propriamente dita e esta sexta fase, denominada "Desenvolvimento do anteprojeto", teve a duração de cinco encontros nos quais as duplas tiveram atendimento personalizado com horário marcado. Na sétima etapa, "Apresentação ao cliente" (no caso, à professora), as duplas apresentaram a toda turma seus cartazes finalizados bem como um cartão em formato A6, isto é, $14,8 \times 10,5 \mathrm{~cm}$ (Figura 1) com o resumo da proposta e com os logotipos das instituições envolvidas; bem como um CD rotulado com todos os arquivos do projeto.

Simões Lopes Neto por e por

Texto conceito em papel A6, gramatura alta, nesta diagramação, texto na lingua vernácula escrito em 1 parágrafo, respeitando o limite definido de 800 caracteres com espaço. O texto deve ser escrito empregando tipografia Times New Roman 12 bold para o titulo, sendo a mesma com tamanho 11 para o restante em espaço simples e com margens estreitas. Deve conter breve histórico dos designers escolhidos e explicação da relação sintática ou semântica definida pela dupla de alunos bem como deve situar os cartazes no rojeto Biênio Simoniano. Texto conceito em papel A6, gramatura alta, nesta diagramação, texto na lingua vernácula escrito em 1 parágrafo, respeitando o limite definido de 800 caracteres com espaço. $O$ deve ser escrito empregando tipografia Times New Roman 12 bold para o título, sendo.

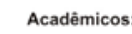

LOGO1 LOGO2 LOGO3

Figura 1: Cartão A6 com resumo da proposta.

Fonte: "Elaborado pelo autor, com base na pesquisa realizada", 2015

As três etapas finais "Organização da produção original final com especificações técnicas", "Supervisão da implementação" e "Avaliação" (ajustes eventuais baseados na avaliação) não foram perpassadas na medida em que o projeto não foi executado de forma industrial, restringindo-se a uma atividade acadêmica hipotética. Como resultado, após a experiência teórico-prática em quatorze encontros semanais de cem minutos cada, os alunos apresentaram os projetos de cartazes abaixo relacionados (Figuras 2 a 12). Os resumos entregues no cartão A6 supracitado - nos quais os alunos tentam fazer breve descrição e análise - são apresentados, ipsis litteris, abaixo das imagens que foram organizadas e diagramadas pelo acadêmico Kauê Xavier, bolsista de iniciação científica PBIP-AF/CNPq. 


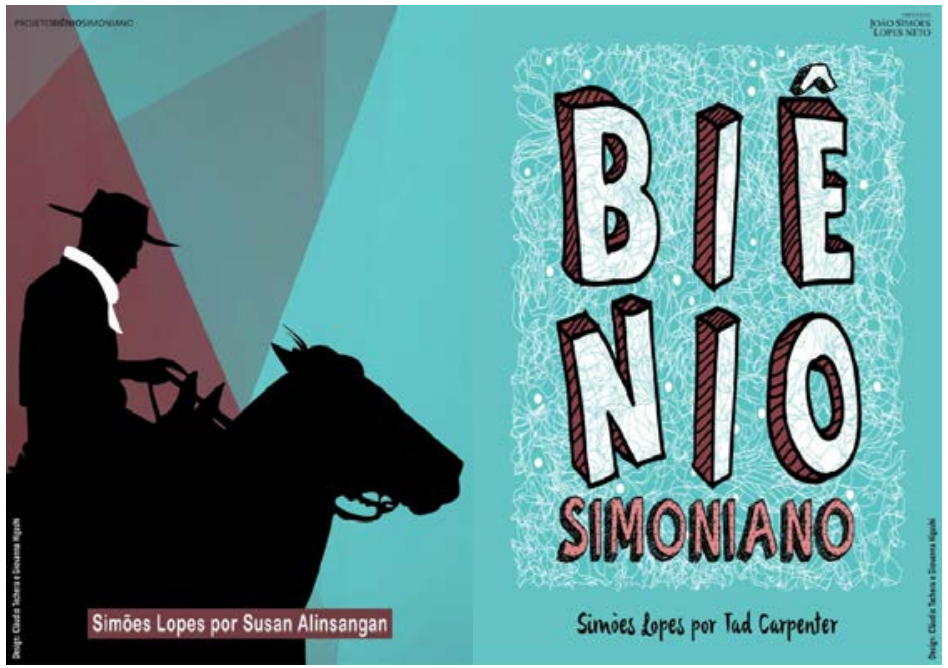

Figura 2: SLN por Susan Alinsangan e por Tad Carpenter.

Fonte: Acadêmicos Cláudio Techera e Giovanna Higashi, 2015

"Simões Lopes, escritor regional pelotense, retrata ao longo de sua vida contos e histórias com temática folclórica gaúcha. Em homenagem ao seu nascimento e morte, escolhemos os artistas Susan Alinsangan e Tad Carpenter. A primeira é diretora de arte responsável pela campanha "iPod Nano", cujas imagens contêm silhuetas em preto e cores vibrantes; o segundo projeta cartazes voltados à ilustração, sendo alguns deles tipográficos. Os cartazes reproduzidos possuem estrutura complementar, um mais minimalista e o outro mais informativo".
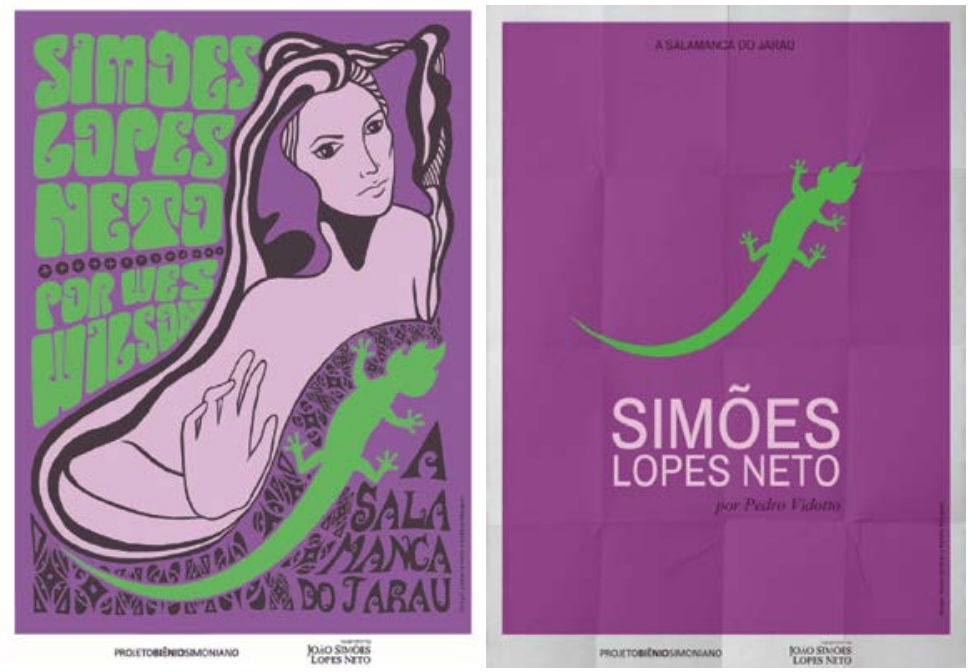

Figura 3: SLN por Wes Wilson e por Pedro Vidotto.

Fonte: Acadêmicas Eloise Schmitz e Natália Marques, 2015

"Considerado o maior autor regionalista do Rio Grande do Sul, o escritor pelotense Simões Lopes é homenageado no Biênio Simoniano durante 2015 e 2016. Inseridas no projeto criamos uma dupla de cartazes inspirados pelo conto A Salamanca do Jarau a partir do americano Wes Wilson, conhecido pela criação de cartazes psicodélicos nos anos 1960 e 1970, e do brasileiro Pedro Vidotto, com seus redesign de cartazes de filmes no estilo minimalista. Ambos compartilham as características das 
cores e a representação da Salamanca. Escolhemos dois artistas com estilos paradoxais para, assim, criar contraste entre a dupla: enquanto um é composto por vários elementos o outro é escasso, fazendo com que se equilibrem juntos".

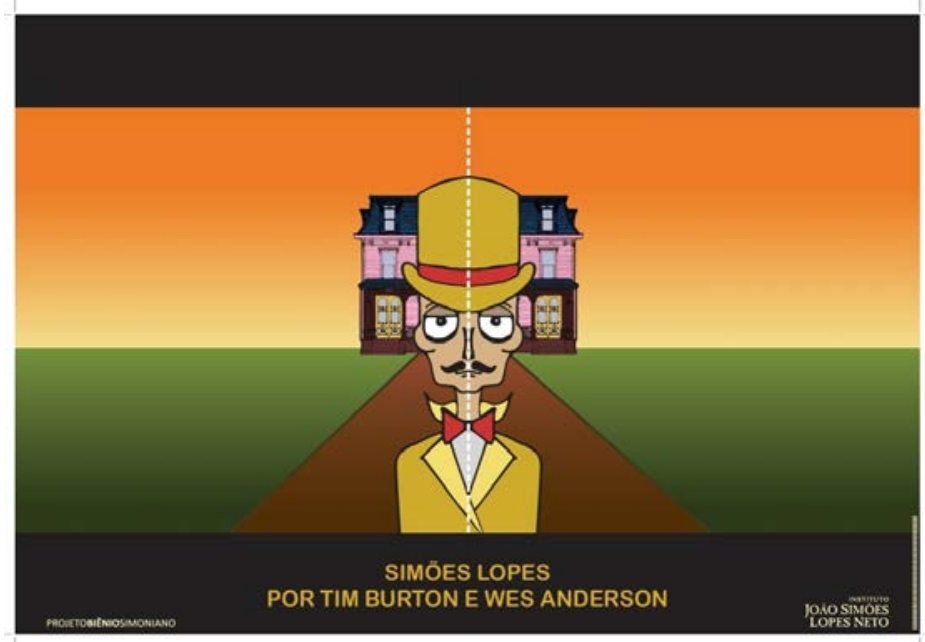

Figura 4: SLN por Tim Burton e por Wes Anderson.

Fonte: Acadêmicos Felipe Albano e Felipe Brandão, 2015

"Os cartazes que homenageiam os 150 anos de nascimento do escritor e empresário pelotense Simões Lopes representam o conto Trezentas Onças a partir de dois cineastas. Tim Burton, com sua atmosfera macabra, sombria e caótica, influencia a estética dos elementos, o tropeiro e a casa. Wes Anderson inspira a composição com a divisão vertical que reforça a simetria, e com cores complementares e espaços vazios característicos de seus filmes. Duas faixas pretas, uma no alto e outra na base, cortam a imagem como um frame cinematográfico. Uma linha tracejada separa os cartazes simetricamente um em relação ao outro".

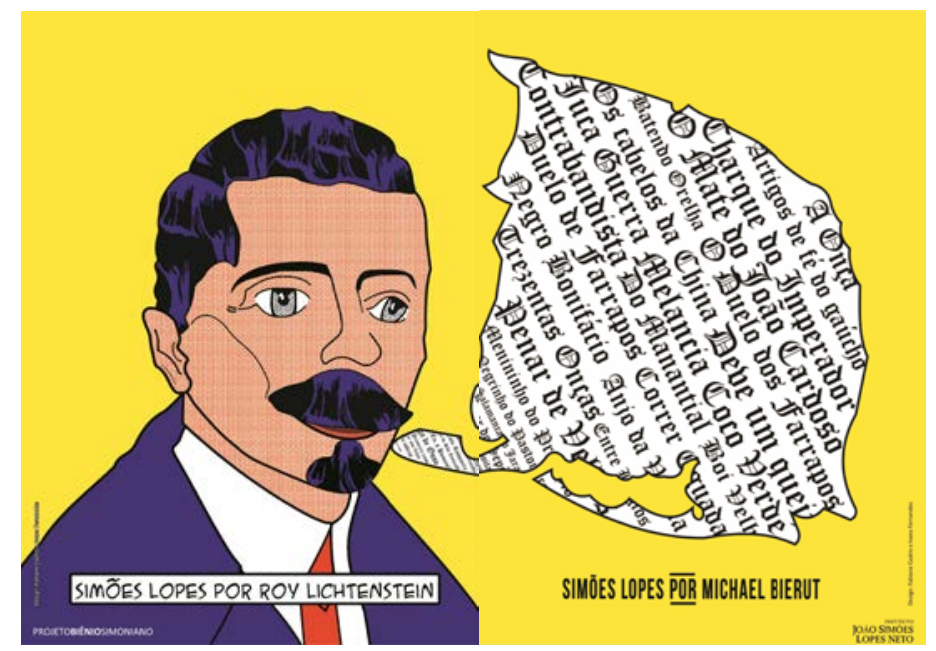

Figura 5: SLN por Roy Lichtenstein e por Michael Bierut.

Fonte: Acadêmicas Fabiane Castro e Ivana Fernandes, 2015

"João Simões Lopes Neto é autor regionalista cujos maiores sucessos são os livros Contos Gauchescos e Lendas do Sul. O Projeto Biênio Simoniano busca 
homenageá-lo através do projeto de uma dupla de cartazes. No primeiro, inspirado no pintor da Pop Art Roy Lichenstein, criamos uma ilustração a partir de uma fotografia de Simões Lopes. No segundo cartaz representamos o mapa do Rio Grande do Sul construído com os títulos de seus livros, e, para tal nos inspiramos no estilo do designer gráfico Michael Bierut. Na junção dos projetos, sugerimos a imagem de Simões Lopes relatando seus contos através de um balão de fala na forma do RS, característica visual muito encontrada nas obras Pop Art".

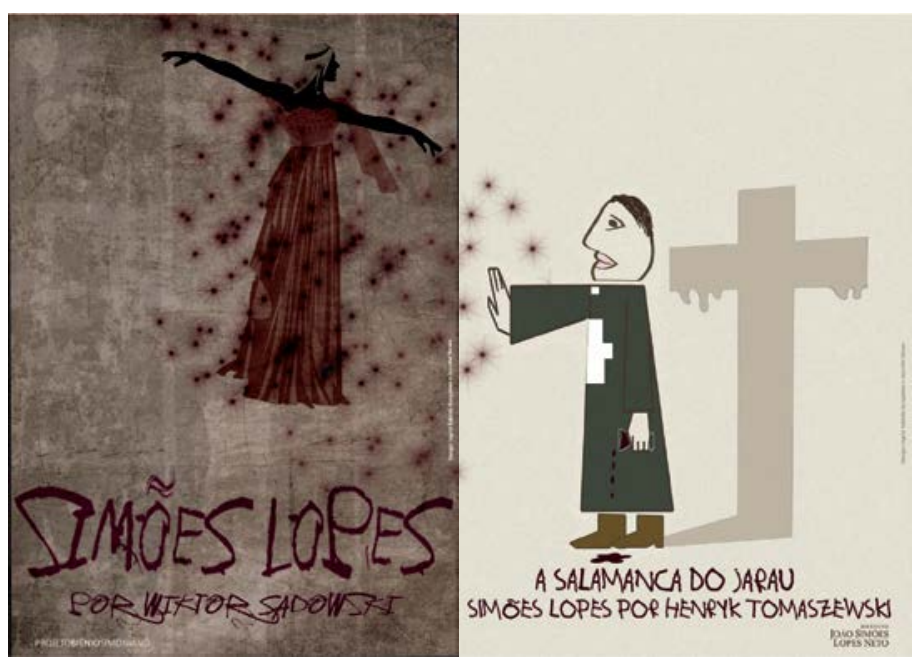

Figura 6: SLN por Henryk Tomaszewski e Witor Sadowski.

Fonte: Acadêmicas Ingrid Gonçalves e Jennifer Neves, 2015

“João Simões Lopes Neto, um dos maiores autores regionalistas do Rio Grande do Sul, valoriza, em sua produção literária, a cultura e as tradições gaúchas. Os cartazes criados, no Projeto Biênio Simoniano, representam os dois personagens principais do conto A Salamanca do Jarau separados, um em cada peça, para ilustrar o amor impossível entre os dois; porém conectados pelo olhar. No primeiro cartaz homenageamos Wiktor Sadowski, cartazista polonês, reconhecido e aplaudido por misturar arte e publicidade; no segundo cartaz reverenciamos Henryk Tomaszewski, também cartazista polonês, cuja força de suas gráficas reside na simplicidade e inteligência".
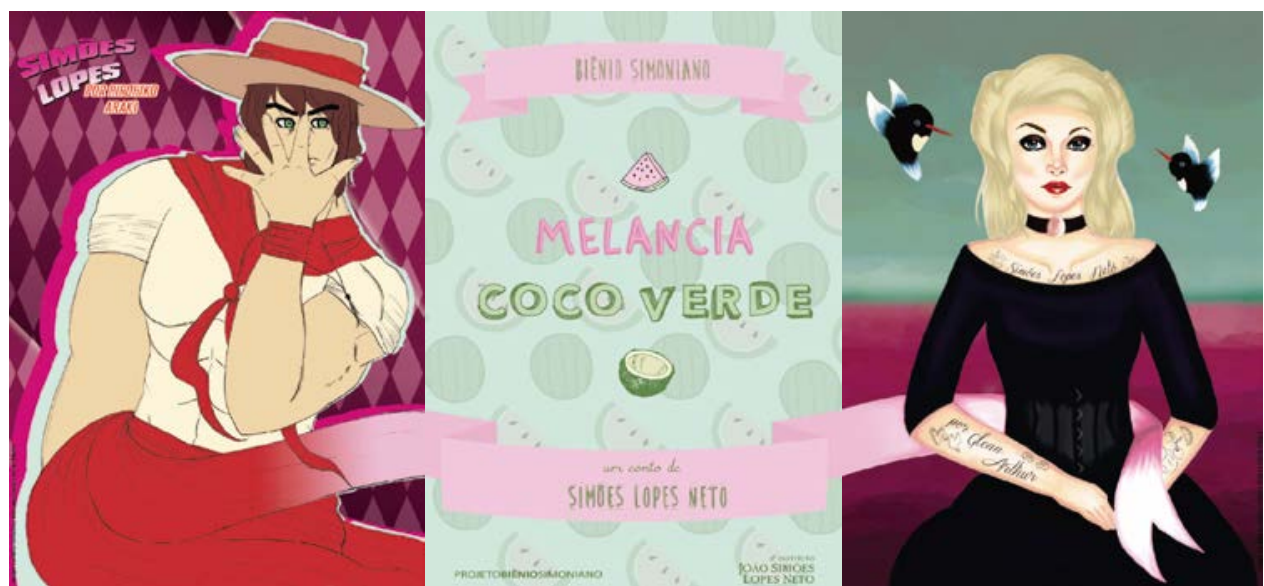

Figura 7: SLN por Hirohiko Araki e Glenn Arthur.

Fonte: Acadêmicas Marcelle Ulliano, Nicole Ribeiro e Carolina Tanabe, 2015 
"Simões Lopes, escritor pelotense, é considerado o maior autor regionalista do RS. Os cartazes narram o conto Melancia: Coco Verde que descreve o romance proibido entre Costinha e Siá Talapa a partir do estilo de Hirohiko Araki, conhecido por sua obra Jojo's Bizarre Adventure e seu traço marcante e peculiar, e do estilo de Glenn Arthur, ilustrador norte-americano dotado de traços delicados e influenciados pelo movimento Art Nouveau. No primeiro cartaz, Costinha é representado como um peão humilde e de garra e, no segundo, Siá Talapa, aparece como uma prenda da classe alta. O cartaz tipográfico posicionado ao centro representa as dificuldades do casal por pertencerem a classes sociais diferentes e a fita, o sentimento puro que os une".

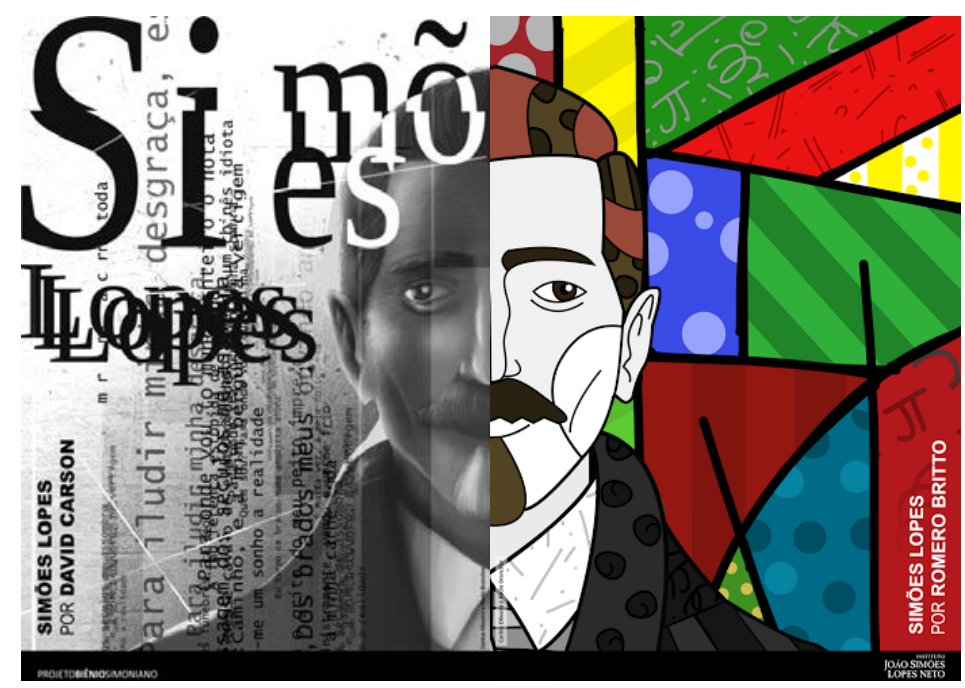

Figura 8: SLN por Simões Lopes por David Carson e por Romero Britto.

Fonte: Acadêmicos Corina Oliveira e Paulo Cesar, 2015

"Simões Lopes é escritor gaúcho e criador de várias obras temáticas, dentre elas Contos Gauchescos. Representamos os cartazes no estilo de diferentes designers e buscamos Racionalidade versus Emoção, representadas pelas imagens do rosto de Simões Lopes modificado nos estilos dos designers David Carson e Romero Britto. David Carson é um designer gráfico americano, conhecido pelo seu trabalho em design de revistas. Para representar a racionalidade, usamos citações da obra de Simões Lopes organizadas com tipografias a partir do seu estilo. Romero Britto é um artista pop brasileiro cujas obras abstratas contêm as mais diversas cores. Inspirado neste, o segundo cartaz representa a criatividade e a emoção". 


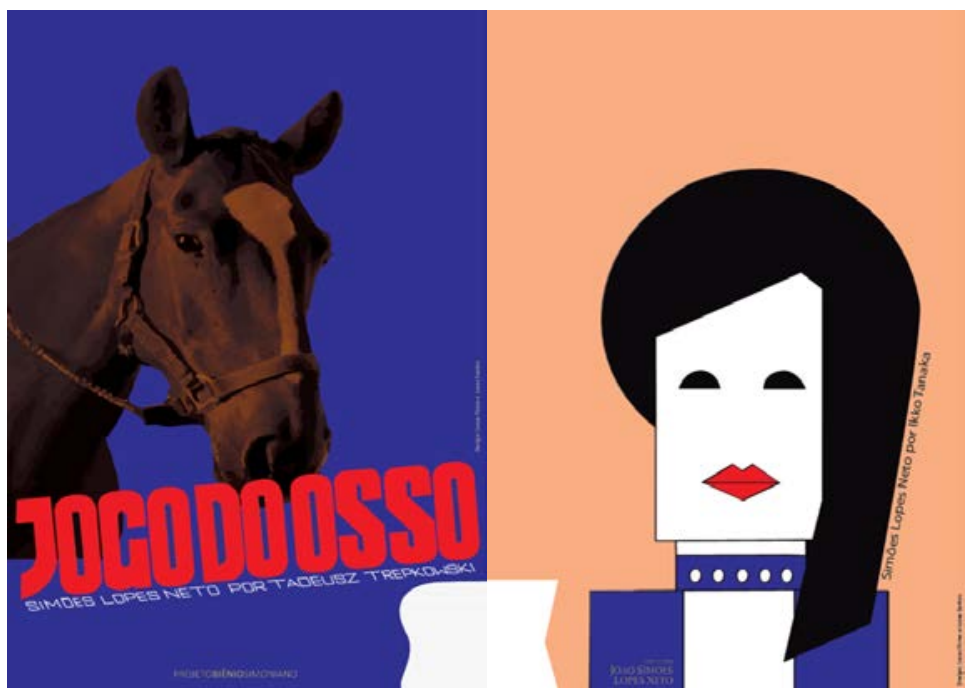

Figura 9: SLN por Tadusz Trepkowski e Ikko Tanaka. Fonte: Acadêmicos Lucas Firmo e Lucas Santos, 2015

"Simões Lopes é, segundo estudiosos, o maior autor regionalista do RS, pois procura, em sua produção literária, valorizar a história do gaúcho e suas tradições. Em nosso projeto, dois cartazes contaram a história do Jogo do Osso. O primeiro retrata o cavalo apostado no jogo e, no segundo, a mulher dada sob aposta por um dos jogadores; separadamente os cartazes podem ser difíceis de ser interpretados, porém, lado a lado, é de fácil compreensão. Foram homenageados Trepkowski, cartazista polonês e Tanaka, artista japonês e suas formas geométricas de tradição milenar".

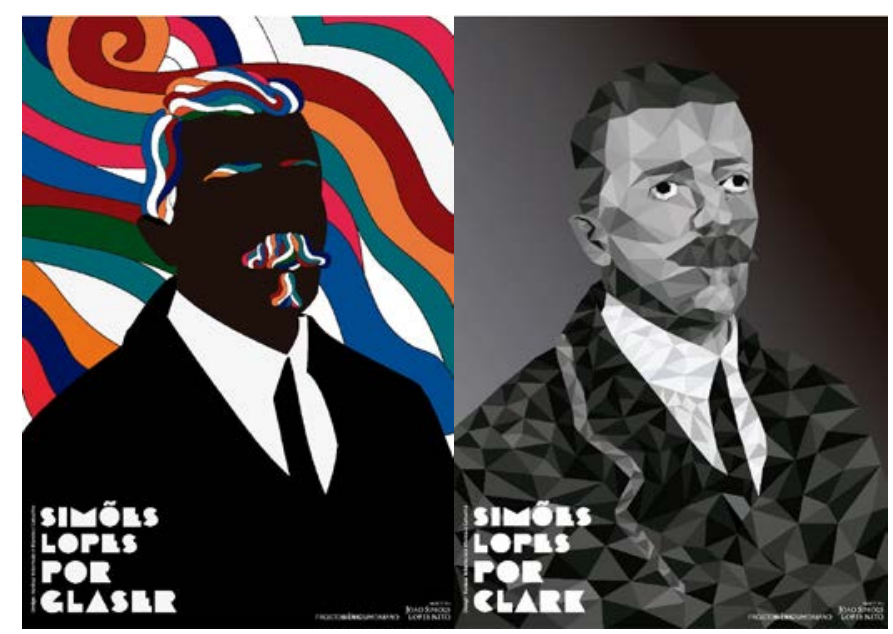

Figura 10: SLN por Milton Glaser e por Lygia Clark.

Fonte: Acadêmicas Karissa Yokemura e Maressa Carvalho, 2015

"João Simões Lopes Neto é considerado por críticos o maior regionalista do Rio Grande do Sul, por sua obra Contos Gauchescos e pelo fato de procurar valorizar a tradição e a história gaúcha. Em homenagem aos 150 anos de seu nascimento, o Projeto Biênio Simoniano aborda a produção de cartazes inspirados em obras de artistas modernos e pós-modernos. Os cartazes trazem uma foto de Simões, que varia de acordo com o designer inspirado. O cartaz à esquerda é inspirado nas obras de 
Milton Glaser, designer norte-americano, reconhecido pela criação da campanha "I Love NY" e pelo cartaz de Bob Dylan. O cartaz à direita é inspirado em Lygia Clark, pintora e escultora brasileira e em sua obra Bichos, onde ela usa materiais moles, como a borracha, para que o expectador possa movê-la e modificá-la".

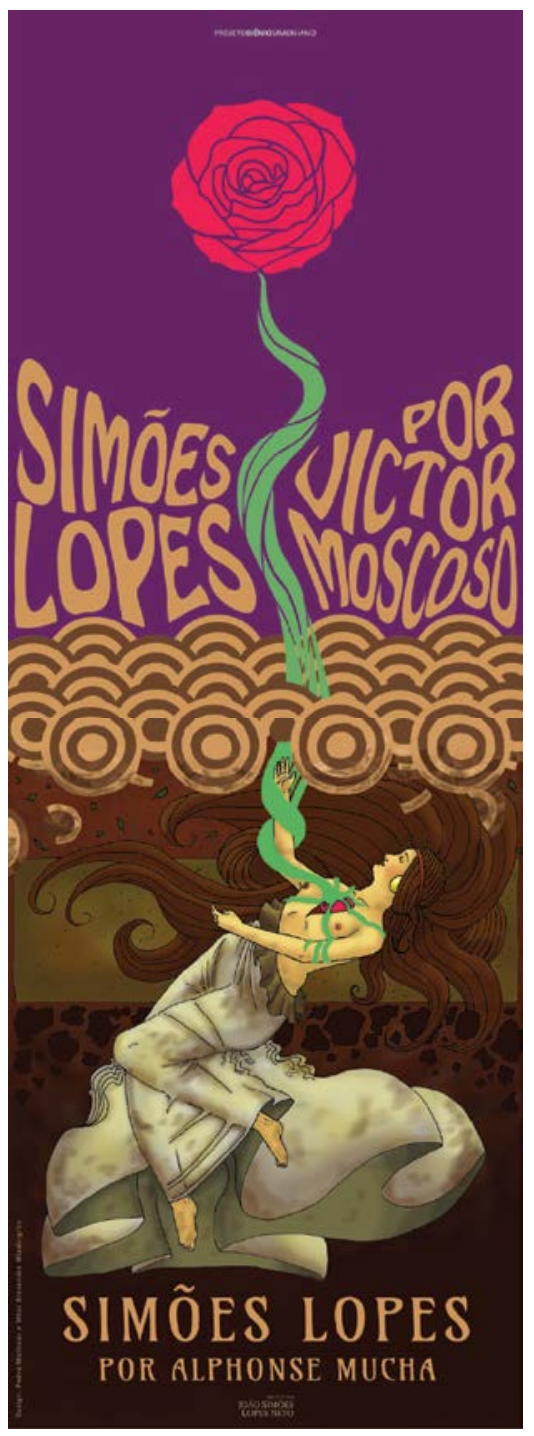

Figura 11: SLN por Alphonse Mucha e por Victor Moscoso.

Fonte: Acadêmicos Pedro Matheus e Vitor Alexandre Wiedergrün, 2015

“João Simões Lopes Neto, escritor e crítico literário pelotense, é considerado um dos maiores autores regionalistas do Rio Grande do Sul. O Projeto Biênio Simoniano faz homenagem ao conto No Manantial presente em seu livro Contos Gauchescos. Sendo assim, no cartaz superior, a composição é baseada em Victor Moscoso, um dos principais artistas americanos do movimento psicodélico nas décadas de 1960 e 1970. Já a outra peça gráfica, posicionada abaixo, tem estilo inspirado em Alphonse Mucha, designer gráfico checo de grande relevância no movimento Art Nouveau com suas ilustrações idealizadas entre as décadas de $1890 \mathrm{e}$ 1930. A relação dos cartazes se estabelece através de um caule, que conecta o coração à rosa, a qual se mantém do sangue de Maria Altina". 


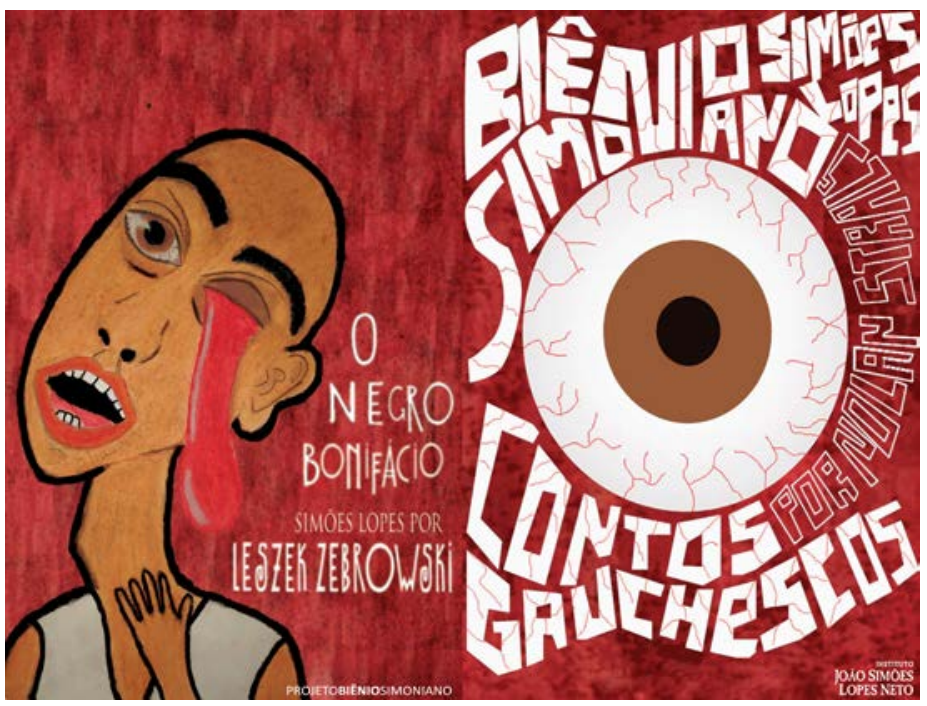

Figura 12: SLN por Leszek Zebrowski e por Nolen Strals.

Fonte: Acadêmicos Bianca Oliveira e Lucas Basílio, 2015

"João Simões Lopes Neto, escritor pelotense, tinha grande interesse pelo resgate da cultura gaúcha. Em 1912, publicou Contos Gauchescos, obras que o notabilizou como um dos maiores escritores da literatura do Rio Grande do Sul. O Projeto Biênio Simoniano contempla a criação de dois cartazes, cada qual com inspiração em um artista diferente, todavia, na mesma sintonia. O cartaz inspirado em Leszek Zebrowski utiliza texturas para remeter ao estilo do artista; já o segundo, inspirado em Nolen Strals, busca o estilo psicodélico com ênfase em tipografia. Os dois cartazes dialogam na medida em que tratam do mesmo conto, O Negro Bonifácio, representando graficamente o clímax da história, isto é, o momento em que Bonifácio é ferido".

\section{CONCLUSÃO}

Não é objetivo deste artigo a análise das imagens apresentadas tampouco uma síntese dessa produção uma vez que pesquisa específica pra esse fim está em andamento em projetos de pesquisa correlacionados; a produção de cartazes destes últimos anos tem se mostrado profícua em quantidade e em qualidade e sua análise demanda outro tempo e espaço.

Nestes últimos três anos, o exercício com temáticas, variadas e transitórias, na disciplina Projeto de Cartaz, sobretudo ligadas à história ou à agenda do momento, tem sido bastante satisfatório na medida em que o aluno, calouro recém saído da escola, chega à universidade com uma cultura bastante geral e ainda pouco atrelada às suas especificidades tão caras ao pleno fazer do designer, como arte, cinema, literatura, música, dentre outras. No mesmo sentido, a atividade pedagógica com foco em um importante autor da literatura gaúcha, no caso em questão, para um público em sua maioria oriundo de outros estados brasileiros também me parece muito oportuna em termos de contextualização cultural específica.

Soma-se a isso a constatação de que o exercício de estrutura basilar, semelhante e recorrente, aqui apresentado, tem possibilitado que, já no início do curso, o aluno tenha acesso a grandes nomes da história moderna e pós-moderna do 
design e da arte bem como aos princípios visuais característicos da prática projetual associados às teorias do cartaz, peça gráfica emblemática no campo do design haja vista sua inerente condição expressiva e, logo, autoral. Ao final, podemos inferir que a presente metodologia de ensino e de projeto pode auxiliar outros professores e pesquisadores de design tanto em suas transitoriedades temáticas - ao aproximar a cultura em geral do design gráfico - quanto em suas estruturas mais fundamentais e perenes.

\section{REFERÊNCIAS}

AMBROSE, Gavin; HARRIS, Paul. Fundamentos de Design Criativo. Porto Alegre, Bookman, 2009.

BARNICOAT, John. Los Carteles: su historia y su lenguaje. Gustavo Gili, 1999.

BOTH, Jorre; BURGER, Sefanie; JONG, Cees de. New pôster art. New York City: Thames and Hudson.

FRASCARA, Jorge. El diseño de comunicación. Buenos Aires: Infinito, 2006.

JONG, Cees de. The poster: 1000 posters from Toulouse Lautrec to Sagmeister. New York: Abrams, 2010.

LUPTON, Ellen; PHILLIPS, Jennifer Cole. Novos Fundamentos do design. São Paulo:

Cosac \&Naify, 2008.

MEGGS, Philip. A History of Graphic Design. 3. ed., New York: Wiley, 1998. 